\title{
Prophylactic vertebral augmentation in patients with intra-disc leakage after kyphoplasty
}

\author{
Ji-Le Jiang, Ya-Jun Liu, Bin Xiao, Gui-Lin Zhang, Wei Tian \\ Department of Spine Surgery, Beijing Jishuitan Hospital, Beijing, China \\ Contributions: (I) Conception and design: JL Jiang, GL Zhang, W Tian; (II) Administrative support: W Tian; (III) Provision of study materials or \\ patients: GL Zhang, W Tian; (IV) Collection and assembly of data: YJ Liu, B Xiao, GL Zhang; (V) Data analysis and interpretation: All authors; (VI) \\ Manuscript writing: All authors; (VII) Final approval of manuscript: All authors. \\ Correspondence to: Wei Tian, MD, PhD. Department of Spine Surgery, Beijing Jishuitan Hospital, 31 Xinjiekou East Street, Beijing 100035, China. \\ Email: tianwjst@126.com.
}

\begin{abstract}
Backgroundk A uperior adjacent vertebral fracture (SAVF) is a common complication after kyphoplasty. Intra-disc leakage is a significant risk factor of SAVF. However, to date, no studies on the prevention of SAVF after intra-disc leakage have been conducted. This study sought to evaluate the clinical outcome of prophylactic vertebral augmentation in high-risk patients, and explore the other risk factors of SAVF.

Methods: Of 2,571 patients who received kyphoplasty, 82 with intra-disc leakage were retrospectively enrolled in the study, and divided into 2 groups based on whether they had a superior level of prophylactic vertebral augmentation. To ensure that any possible early complications were examined, there was a minimum follow-up period of 12 months.
\end{abstract}

Results: The pre-operation parameters were comparable between the 2 groups. In the non-prophylactic group, 9 of $59(15.3 \%)$ patients had SAVF superior to the level of intra-disc leakage. Of these 9 SAVF cases, 8 fractures $(88.9 \%)$ occurred within 6 months after surgery. Overall, 14 (23.7\%) patients developed a new fracture. In the prophylactic group, no patients had a SAVF $(0.0 \%)$, but $3(13.0 \%)$ had remote fractures $(\mathrm{P}=0.047$ and 0.284$)$. No complications were associated with vertebral augmentation. Further, the risk factor analysis showed that patients with comorbidities and a history of corticoid use had a higher risk of fracture compared with patients with none of these risk factor [odds ratios: 12.0, 95\% confidence interval (CI): 1.0143, and 34.3, 95\% CI: 3.2-364.5, respectively].

Conclusions: Prophylactic vertebral augmentation can prevent SAVF without complications. Patients with comorbidities and a history of corticoid use had a higher risk of SAVF compared with patients without corticoid use. Thus, we recommend prophylactic vertebral augmentation in the selected high-risk patients.

Keywords: Osteoporosis vertebral compression fracture (OVCF); balloon kyphoplasty; adjacent vertebral fracture; cement leakage; prophylactic cement augmentation

Submitted Mar 16, 2021. Accepted for publication May 06, 2021.

doi: $10.21037 /$ apm-21-867

View this article at: http://dx.doi.org/10.21037/apm-21-867

\section{Introduction}

A vertebral compression fracture is a common fracture in elderly patients with osteoporosis (1). Such factures cause heavy health and economic burdens for society (2). Since its introduction by Garfin et al. (3), balloon kyphoplasty (BKP) has been used for vertebral compression fractures, as it is safer and has better correction powers than vertebroplasty. Despite some controversies about the treatment efficacy of BKP, it is still widely used in the treatment of acute or subacute osteoporotic vertebral compression fractures, as it can relieve pain, enable early mobilization, and thus improve patients' quality of life $(4,5)$.

BKP is considered a safe treatment (6); however, 
it is still associated with complications (7). Of these complications, the most common is a new vertebral fracture postoperatively; however, it should be noted that debate continues as to whether such new factures are a consequence of osteoporosis $(1,8)$. New fracture after BKP included remote fracture, inferior vertebral fracture and so on. Among new fractures, the superior adjacent vertebrae fracture (SAVF) has gained considerable attention, as it happens early (i.e., within 6 months of surgery) (9) and accounts for most new fractures (54-66\%) (6). It is a specific type of vertebral compression fracture that is directly correlated with kyphoplasty. Due to the short time interval, this fracture decreases patients' satisfaction and quality of life. Thus, research needs to be conducted to identify the risk factors of SAVF and reduce its incidence.

Among all the risk factors of a new fracture after BKP, intra-disc cement leakage is a critical one (9-11). Unlike other risk factors, such as a first vertebral fracture, intradisc leakage can be partially controlled by the surgeon, and is common in patients who have undergone BKP (6). Thus, the prevention of SAVF is critical in high-risk patients, such as those with intra-disc leakage. However, no clinical research has focused on how to prevent such complications after intra-disc leakage.

We performed experimental prophylactic vertebral augmentations superior to the fractured vertebrae level, and conducted a retrospective cohort study. This study sought to (I) compare clinical outcomes between patients with and without prophylactic vertebral augmentation, and (II) determine the risk factors of SAVF after BKP in patients with intra-disc leakage. We present the following article in accordance with the STROBE reporting checklist (available at http://dx.doi.org/10.21037/apm-21-867).

\section{Methods}

Retrospective cohort study was designed and the fundamental research can be divided into 2 parts: (I) clinical outcomes and the safety of prophylactic vertebral augmentation; and (II) a risk factor analysis of SAVF after intra-disc leakage. We selected patients who underwent kyphoplasty between January 2013 and June 2015 at our hospital. To be eligible for inclusion in this study, patients had to meet the following inclusion criteria: (I) have cement leaking into the superior intra-disc space; (II) have an intact superior vertebra. Intra-disc leakage was confirmed by fluoroscopy intra-operatively; and (III) minimum follow- up is 12 months. Patients with pathological compression fractures (e.g., metastasis or multiple myeloma) were excluded. All patients were selected according to the inclusion and exclusion criteria to reduce selection bias. The study was designed and conducted following the international guidelines, and was approved and guided by the Ethics Committee of the Beijing Jishuitan Hospital (No. 202012-01) and the director of the Spine Department. All procedures performed in this study involving human participants were in accordance with the Declaration of Helsinki (as revised in 2013).

Surgery was performed in patients with an acute osteoporosis vertebral compression fracture (OVCF) who could not tolerate pain or were bed-ridden and those with subacute OVCF who failed to respond to conservative treatment. All patients underwent magnetic resonance imaging (MRI) preoperatively to ensure that the fracture was fresh. If a patient was contraindicated to undergo MRI, an isotope bone scan was used as a substitute. Patients' general information, including age, sex, visual analog scale (VAS) score, and fractured vertebrae level, were collected, and lumbar quantitative computed tomography (QCT) was used to evaluate patients' bone density.

All patients were made aware of the potential complications, including cement leakage and possible prophylactic vertebral augmentation. Both verbal and written consent about prophylactic vertebral augmentation was obtained before surgery. The criteria for prophylactic operation were based on the surgeon's decision, including intra-disc leakage, if the patient was elderly (i.e., aged over 60), and a low QCT (lower than $80 \mathrm{mg} / \mathrm{cc}$ ).

\section{Procedure}

The procedure was conducted under local anesthesia, and a bilateral approach was used if a single approach could not restore the vertebra. In patients with intra-disc leakage, prophylactic superior vertebral augmentation was performed at the surgeon's discretion (see Figure 1). Finally, the cement volume of each vertebra was collected.

\section{Post-operation}

Patients were encouraged to ambulate after bed rest for 3 hours, and return to regular activity gradually. However, a thoracolumbar brace restricting flexion and extension was recommended when sitting or walking. Medication for 

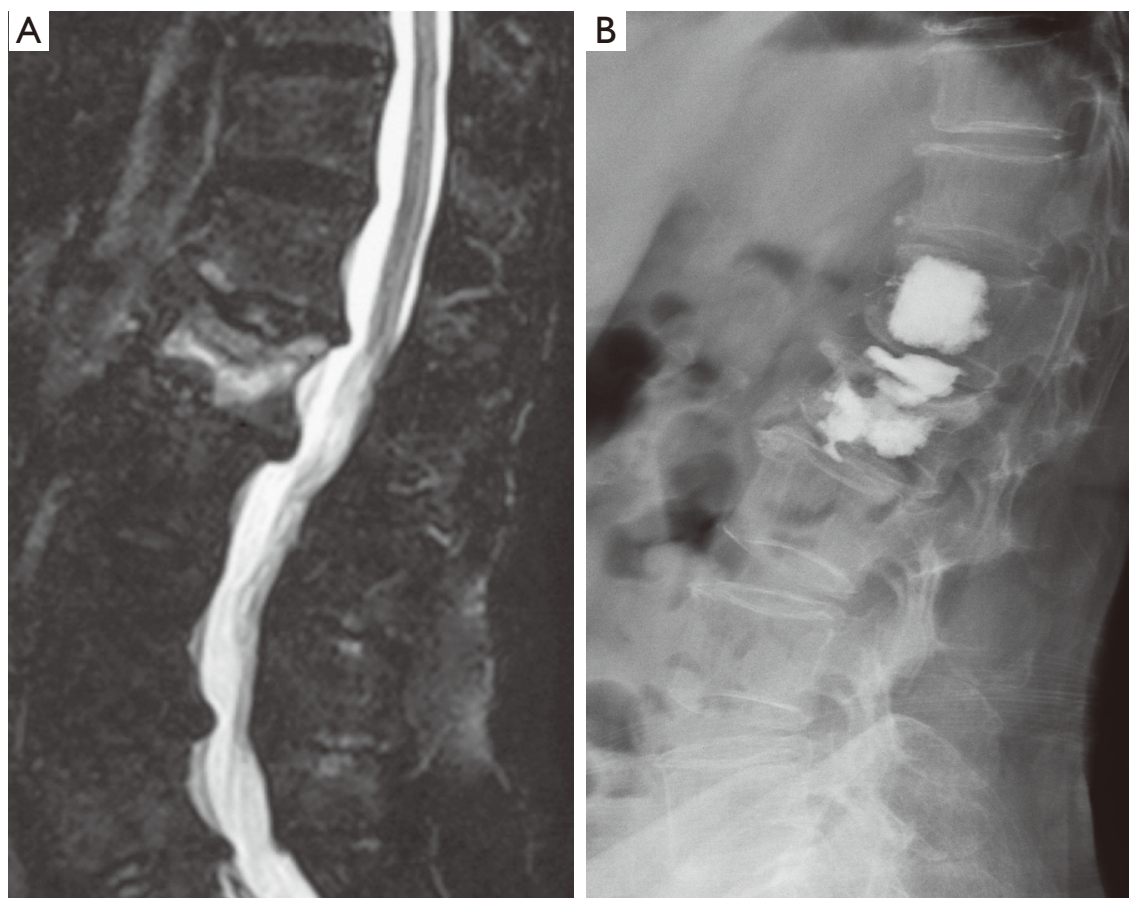

Figure 1 Prophylactic vertebral augmentation after intra-disc leakage. (A) Fat compressive T2-weighted images showing L2 vertebra fracture, and the superior vertebral (L1) intact; (B) major cement leakage in L1/L2 intervertebral space, the L1 level is prophylactically augmented.

osteoporosis was provided by endocrine or family doctors during follow-up appointments. Patients were evaluated radiographically 3,6 , and 12 months postoperatively. Further follow-up appointments were conducted via telephone to check whether patients had symptomatic back pain or other complications. The VAS score was recorded at the last follow-up appointment.

If patients suffered from second back pain, radiography and MRI were used to make a diagnosis. The indication and procedure for the second operation were the same as those for the first operation (see Figure 2).

In relation to the radiological evaluation, the intra-disc space was divided into 3 parts (i.e., the anterior, middle, and the posterior third along the superior endplate), and the volume of cement leakage was described as major or minor based on whether it filled more than a quarter of the space as previously described (12) (see Figure 3).

\section{Statistical analysis}

Patients were divided into 2 groups based on whether they received prophylactic vertebral augmentation. In relation to the demographic data, categorical variables are expressed as proportions, and continuous variables are expressed as means, minimums, and maximums. Chi-square tests were performed for the categorical variables. Continuous variables were compared using the Kruskal-Wallis test or the independent Student $\mathrm{t}$-test after the normal distribution test was performed.

In the non-prophylactic group, a univariate logistic regression analysis was used to identify possible risk factors for adjacent vertebral fracture, including age, sex, osteoporosis (QCT, the Z score, and the T score), radiological evidence (the intra-disc cement position and volume), history (a previous fracture in other sites, past comorbidities, and a history of corticoid use), vertebrae levels, and cement use. A multivariate logistic regression analysis was undertaken to further analyze factors with significant correlations. The outcomes were analyzed with the odds ratio and corresponding $95 \%$ confidence intervals (CIs). $\mathrm{P}$ values of 0.05 were considered statistically significant. All analyses were performed using IBM Statistical Package for the Social Sciences, version 19.0 (SPSS Inc.). 

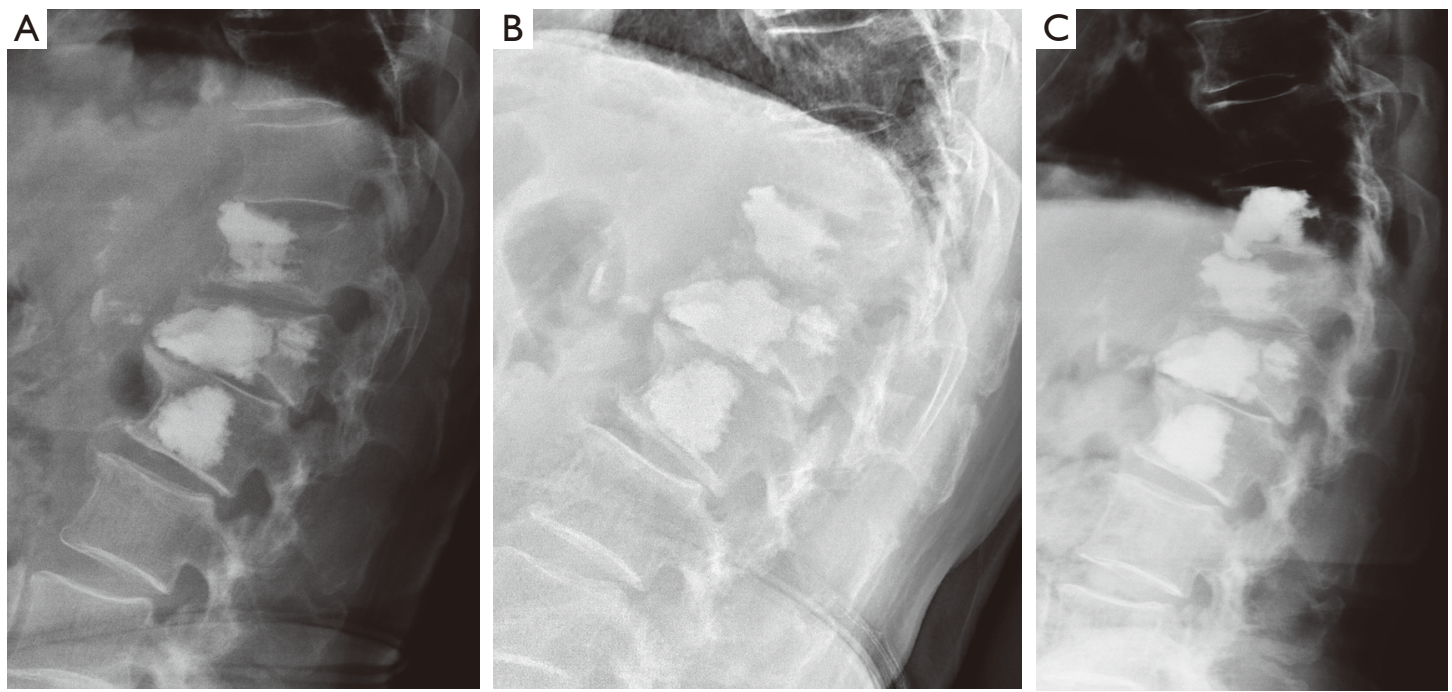

Figure 2 Early adjacent vertebra fracture after balloon kyphoplasty (BKP) with intra-disc leakage. (A) The patient had a T12-L2 vertebra fracture and received BKP, and there was an intra-disc leakage in the T11/T12 intervertebral space in the BKP; (B) 2 months after the first operation, a T11 vertebral compression fracture occurred; (C) the patient received a second BKP for the second fracture.
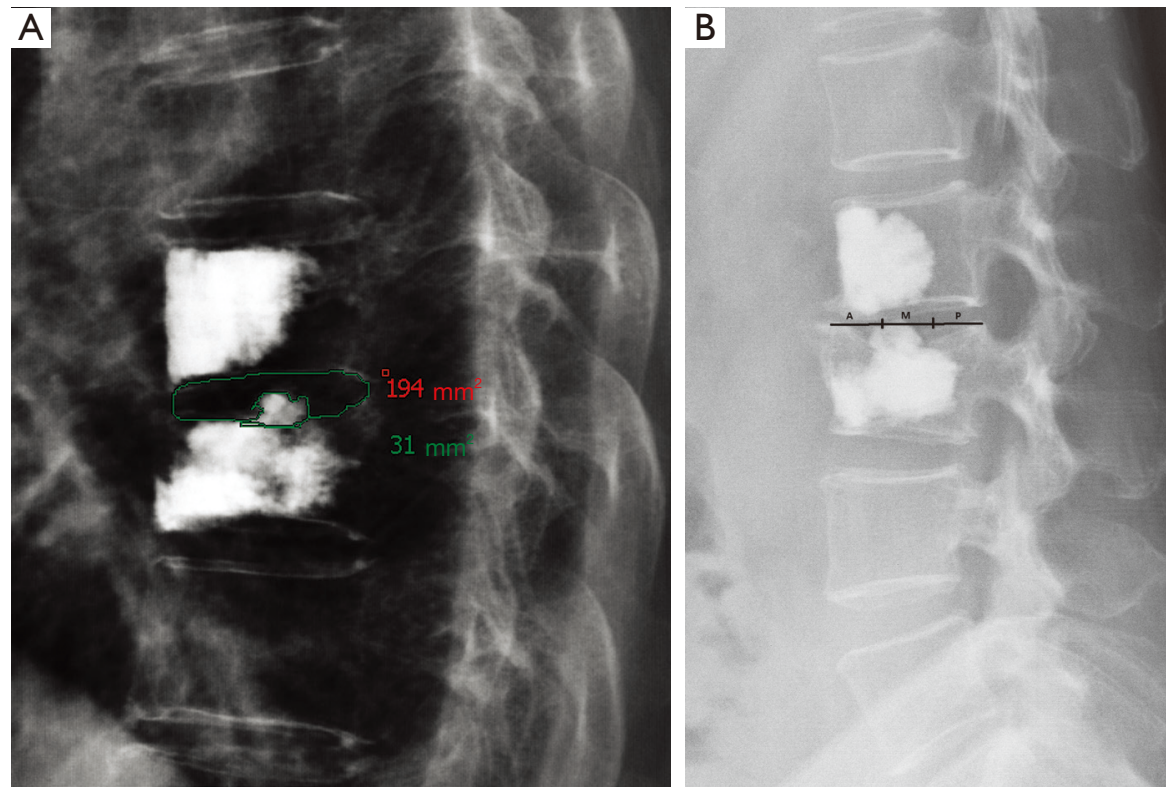

Figure 3 Methods of radiological evaluation. The measurement was performed by drawing a region of interest around the cement and intervertebral space. In this case, (A) it was categorized as middle third; (B) it was categorized as minor as the volume of cement leakage filled less than a quarter of the space. 
Table 1 Distribution of osteoporosis vertebral compression fracture level and the new adjacent vertebral fracture level

\begin{tabular}{|c|c|c|c|c|}
\hline Level & \multicolumn{2}{|c|}{ Fracture } & \multicolumn{2}{|c|}{ Adjacent vertebral fracture } \\
\hline T6 & 0 & 0 & 1 & 11.1 \\
\hline T7 & 4 & 4.9 & 0 & 0 \\
\hline T8 & 3 & 3.7 & 0 & 0 \\
\hline T10 & 1 & 1.2 & 0 & 0 \\
\hline T11 & 10 & 12.2 & 2 & 22.2 \\
\hline T12 & 30 & 36.6 & 3 & 33.3 \\
\hline L1 & 12 & 14.6 & 1 & 11.1 \\
\hline L4 & 4 & 4.9 & 1 & 11.1 \\
\hline L5 & 2 & 2.4 & 0 & 0 \\
\hline
\end{tabular}

\section{Results}

Eighty-two patients with intra-disc leakage were selected from 2,571 patients receiving BKP. Of these patients, 17 were men, and 65 were women. Patients had an average age of 67 (range, 46-84 years). Table 1 shows the fractures and new adjacent vertebral fracture levels. Overall, QCT was $63.3 \mathrm{mg} / \mathrm{cc}$ (range $7.1-128.4 \mathrm{mg} / \mathrm{cc}$ ), the $\mathrm{Z}$ score was -1.51 (range, $-5.16-0.35$ ), and the $\mathrm{T}$ score was -3.82 (range, -6.18-1.54). Of the patients, 12 (14.6\%) had a history of fracture, $41(50 \%)$ had comorbidities, such as hypertension or diabetes (patients with a history of corticoid use were excluded), and 7 (8.5\%) had used corticoids for more than 1 month. On average, $5.1 \mathrm{~mL}$ (range, 1.8-9 mL) of cement was used. The VAS score was 7.1 (range, 4-10) preoperatively, and 1.8 (range, 0-6) postoperatively $(\mathrm{P}=0.000)$. The mean follow-up time was 13.95 months (range, $12-30$ months). Seven (8.5\%) patients had unsatisfactory pain relief, and 17 (20.7\%) experienced a new fracture during the follow-up period. No patients had severe complications, such as spinal cord injury, nerve root injury, allergy, or pulmonary embolization.

Patients were divided into 2 groups. Twenty-three patients received prophylactic vertebral augmentation at the superior vertebra of the intra-disc cement leakage space, and 59 did not receive prophylactic augmentation. The general conditions of patients in both groups are compared in Table 2, and the surgical outcomes are presented in Table 3. Nine (15.3\%) patients had an adjacent vertebral fracture, most of which $(8,88.9 \%)$ occurred in the first 6 months after surgery. Five patients had fractures at other levels. In the augmentation group, $3(13.0 \%)$ patients had new fractures, none of which occurred at the superior level. The incidence of adjacent vertebral fracture was significantly different between the 2 groups $(\mathrm{P}=0.047)$. The details of patients with new fractures are presented in Table 4.

In the augmentation group, $4.4 \mathrm{~mL}$ (range, $2.5-7.5 \mathrm{~mL}$ ) bone cement was used for the fractured vertebrae, while $5.4 \mathrm{~mL}$ (range, $2.0-7.5 \mathrm{~mL}$ ) was injected in the superior level for prophylactic augmentation. Significantly more cement was used in the superior level than for the fractured vertebrae $(\mathrm{P}=0.036)$. In terms of intra-disc leakage, 25 $(30.5 \%)$ cases occurred in the anterior third, $49(59.8 \%)$ occurred in the middle third, and $8(9.8 \%)$ occurred in the posterior third. Overall, 40 (48.8\%) cases were categorized into the major group, and $42(51.2 \%)$ cases were categorized into the minor group. Details of the radiological evidence are shown in Figure 4.

A univariate logistic regression analysis was conducted in the non-prophylactic augmentation group to demonstrate the risk factors of adjacent vertebral fracture, and the results are shown in Table 5. Sex, comorbidities, and corticoid use had a possible correlation with early adjacent vertebral 
Table 2 General conditions of the 2 groups

\begin{tabular}{lccc}
\hline Parameters & Prophylactic & Non-prophylactic & P value \\
\hline Cases & $23(28 \%)$ & $59(72 \%)$ & $13(22.0 \%)$ \\
Male & $4(17.4 \%)$ & $46(78.0 \%)$ & 0.641 \\
Female & $19(82.6 \%)$ & $66.5[46-84]$ & 0.136 \\
Age & $69.7[60-82]$ & $7.0[4-10]$ & 0.856 \\
Pre-op VAS & $7.1[6-9]$ & $63.3(7.7-128.4)$ & 0.996 \\
QCT (mg/cc) & $63.2(21.5-79.6)$ & $-1.52(-3.96$ to 0.35$)$ & 0.915 \\
Z score & $-1.47(-5.16$ to 0.19$)$ & $-3.98(-1.54$ to -6.18) & 0.379 \\
T score & $-3.45(-5.65$ to -2.14$)$ & $7(11.9 \%)$ & 0.256 \\
Past fracture history & $5(21.7 \%)$ & $30(50.8 \%)$ & 0.806 \\
Comorbidities & $11(47.8 \%)$ & $6(10.1 \%)$ & 0.397 \\
Corticoid usage & $1(4.3 \%)$ & $14.8[6-30]$ & 0.160 \\
Follow-up time (months) & $11.7[6-28]$ & $5.2(2-9)$ & 0.037 \\
Cement usage in leakage vertebral $(\mathrm{mL})$ & $4.4(2.5-7.5)$ & & \\
\hline
\end{tabular}

VAS, visual analog scale; QCT, quantitative computed tomography.

Table 3 Surgical outcomes of the 2 groups

\begin{tabular}{lccc}
\hline Parameters & Prophylactic & Non-prophylactic & P value \\
\hline Adjacent vertebral fracture & $0(0.0 \%)$ & $9(15.3 \%)$ & 0.047 \\
Remote vertebral fracture & $3(13.0 \%)$ & $5(8.5 \%)$ & 0.708 \\
Overall vertebral fracture & $3(13.0 \%)$ & $14(23.7 \%)$ & 0.284 \\
Post-op VAS & $1.7[0-5]$ & $1.88[0-6]$ & 0.754 \\
VAS improvement & $5.4[2-9]$ & $5.2[1-9]$ & 0.924 \\
Unsatisfied pain relieve & $2(8.7 \%)$ & $5(8.5 \%)$ & 0.974 \\
\hline
\end{tabular}

VAS, visual analog scale.

fracture $(\mathrm{P}=0.003,0.142$, and 0.002 , respectively). The multivariate logistic regression analysis demonstrated that comorbidities and corticoid use were significantly correlated with fracture [odds ratios: 12.0 (95\% CI: 1.0-143) and 34.3 (95\% CI: 3.2-364.5)].

\section{Discussion}

BKP has been successfully used to treat osteoporotic vertebral compression fractures; however, the risk of a new fracture after BKP remains an issue for patients. Consistent with previous research findings (12-27\%) $(6,12)$, in our study, on average, $20.7 \%$ of patients experienced a second fracture within 14 months of surgery. Further, SAVFs accounted for $57 \%$ of all new fractures in the nonprophylactic group. $88.9 \%$ of fractures occurred within 6 months of surgery. This jeopardizes the surgical effect of BKP, as 15 patients per 100 have to return to hospital for a second surgery within 6 months of their first operation, which decreases patients' quality of life and increases their economic burden (13).

Cement leakage is common in kyphoplasty $(14,15)$. Although upper endplate cortical disruption is not so common in osteoporotic vertebral compress fracture patient, the incidence of intra-disc leakage is reported to be as high as $30 \%$ in patients with endplate cortical disruption (16). 
Table 4 Details of patients with a second fracture after balloon kyphoplasty (BKP)

\begin{tabular}{|c|c|c|c|c|c|c|c|}
\hline Pts & Leakage vertebral & $\begin{array}{l}\text { Cement usage } \\
(\mathrm{mL})\end{array}$ & $\begin{array}{l}\text { Concomitant } \\
\text { fracture }\end{array}$ & Adjacent & New fracture level & $\begin{array}{l}\text { Time to fracture } \\
\text { (month) }\end{array}$ & Mechanism \\
\hline \multicolumn{8}{|c|}{ Non-prophylactic group } \\
\hline 2 & L1 & 6.5 & NA & Yes & $\mathrm{T} 12$ & 6 & Atraumatic \\
\hline 5 & $\mathrm{~T} 12$ & 5.0 & L2, L4 & Yes & T11, L5 & 18 & Atraumatic \\
\hline 6 & L3 & 6.0 & NA & No & L3 & 6 & Atraumatic \\
\hline 7 & $\mathrm{~T} 7$ & 4.0 & $\mathrm{~T} 11$ & No & $\mathrm{T} 12$ & 24 & Fall \\
\hline 11 & L2 & 6.5 & L5 & Yes & L1 & 6 & Atraumatic \\
\hline 12 & L1 & 6.5 & NA & Yes & $\mathrm{T} 12$ & 3 & Atraumatic \\
\hline 13 & $\mathrm{~T} 12$ & 4.5 & L4 & No & T4, T5 & 5 & Fall \\
\hline 14 & $\mathrm{~T} 12$ & 5.0 & T12, L1, L2 & Yes & $\mathrm{T} 11$ & 2 & Atraumatic \\
\hline \multicolumn{8}{|c|}{ Prophylactic group } \\
\hline 1 & $\mathrm{~T} 12$ & 2.5 & NA & No & L2 & 24 & Atraumatic \\
\hline 2 & $\mathrm{~T} 12$ & 3.0 & NA & No & L5 & 3 & Atraumatic \\
\hline
\end{tabular}

*, the patient suffered from a third fracture 1 year after the second BKP; T8 and T9 were involved; ${ }^{+}$, the patient died due to cerebral vascular disease 1 year after the operation.

Mechanical experiments have suggested that cement can increase stress on the superior vertebra, and cause a new fracture in osteoporotic vertebrae (17). A few researchers have argued that intra-disc leakage does not increase the new fracture rate (18), but these researchers failed to focus on superior intra-disc leakage and the specific fracture type of SAVF. It is widely agreed that intra-disc leakage is a significant risk factor for SAVF $(16,19)$. To address this issue, we performed a pilot study on prophylactic vertebral augmentation to prevent SAVF. The results showed that vertebral augmentation could successfully prevent new fractures in the superior adjacent vertebrae $(0 \% v s .15 .3 \%$, $\mathrm{P}=0.047$ ).

Further, no additional complication was induced by augmentation. The new fracture rates of remote vertebrae were similar $(13.0 \%$ vs. $8.5 \%, \mathrm{P}=0.708)$, and no severe complications (e.g., pulmonary embolization or anaphylaxis) occurred. Previous reports have implied that extra cement can increase the new fracture rate (20); however, in our follow-up period, no new fractures occurred in the vertebrae superior to the prophylactic level. This may be because of the intact endplate at the prophylactic level. However, we observed 3 remote vertebral fractures within 3-24 months of surgery.

Prophylactic vertebral augmentation has been discussed in previous studies, and while biomechanical experiments have shown promising results (21-23), a few clinical studies have had controversial results $(24,25)$. Under the inclusion criteria for previous research, all patients who had undergone BKP were included (i.e., the patients included in the research did not have to be high-risk patients). Unlike previous studies, patients had to have a specific condition to be eligible for inclusion in our study (i.e., intra-disc leakage), and we also focused on a specific fracture type (i.e., 

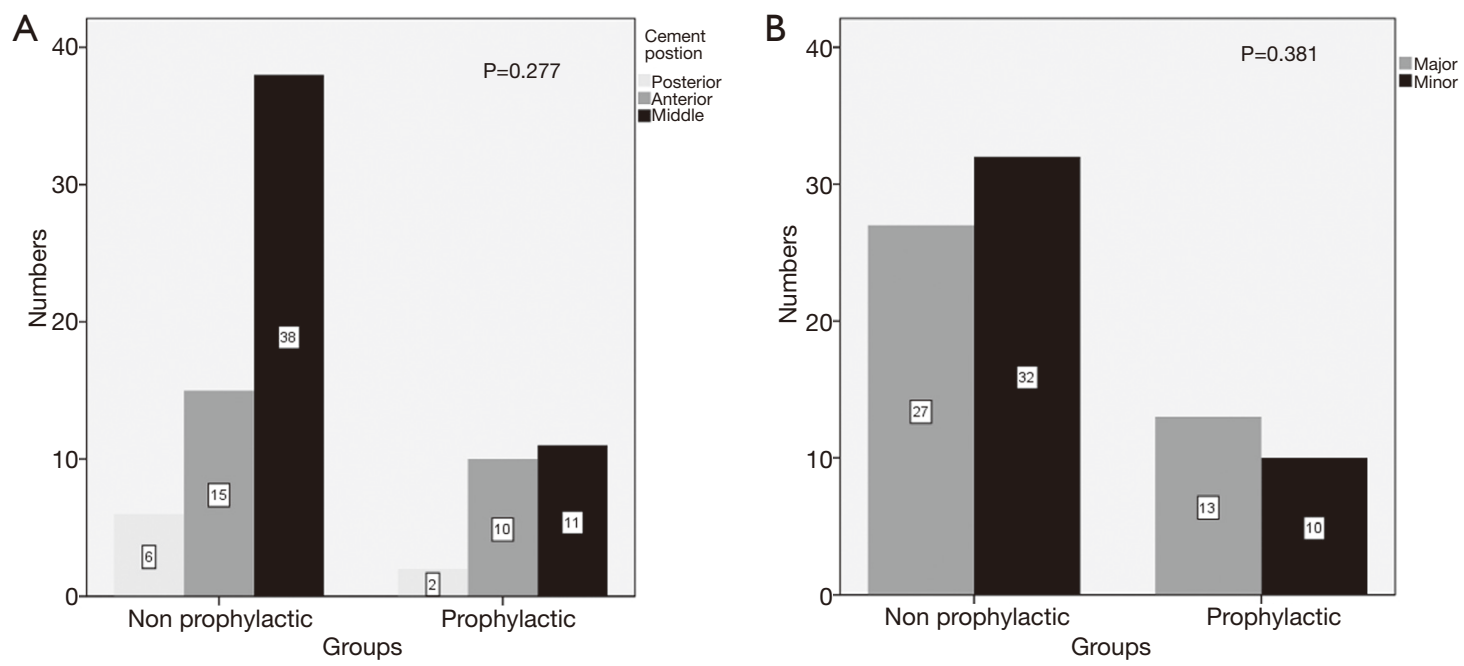

Figure 4 Statistical analysis of the radiological evaluation showed that, (A) there was no significant difference in the distribution of leakage position $(\mathrm{P}=0.277)$, but there was a more significant proportion of the anterior third in the prophylactic group. And (B) there was no significant difference in the volume of leakage position $(\mathrm{P}=0.381)$.

SAVF). The method of preventing fracture by prophylactic cement augmentation has previously been used in adult spinal deformity surgery (26), and has been proven to be clinically successful and cost effective. We conducted the present study using the same method, but we only injected prophylactic cement in high-risk patients.

To identify correlations between cement leakage and a new fracture, some researchers have also categorized intradisc leakage based on position and volume (12). In our study, most leakages occurred in the anterior or middle third (30.5\% and $61.0 \%$, respectively), and $48.8 \%$ of leakage was categorized into the major group. Theoretically, a major leakage will induce more stress on superior vertebrae; however, no correlation was found between the SAVF and leakage position $(\mathrm{P}=0.478)$ or size $(\mathrm{P}=0.618)$.

In addition to intra-disc leakage, previous research has examined many factors as possible reasons for a new fracture, including the vertebra level, sex, fracture history (other sites), osteoporosis, cement volume, and a patient' general condition $(8,9,11,16,19)$. Our results showed that comorbidities and a history of corticoid use were positively correlated with SAVF [odds ratios: 12.0 (95\% CI: $1.0-143$ ) and 34.3 (95\% CI: 3.2-364.5)], which reflects the findings of previous reports (9). Our findings imply that the general condition of patients was more predictive of SAVF than the local condition of patients with intra-disc leakage.

Previous research has shown that osteoporosis of vertebrae predicts fractures (10); however, in our research, osteoporosis parameters (including QCT, the Z score, and the $\mathrm{T}$ score) had no significant correlation with SAVF (0.836, 0.933 , and 0.991 , respectively). This may be because we focused on the SAVF (rather than all new fractures), and QCT may only reflect general osteoporosis (rather than specific vertebra)

Our study had several limitations. First, our small sample size might compromise our conclusions, especially in the risk factor analysis, as the results may produce false negatives due to the weak statistical power. Second, while prophylactic augmentation has been proven to be successful at reducing vertebral fracture risk and preventing a second surgery, a further cost-benefit analysis needs to be undertaken. Our results are only preliminary and our study was conducted on a relatively small scale; however, we intend to conduct further multicenter clinical trials with a larger population in the future.

\section{Conclusions}

Our preliminary study showed that prophylactic vertebral augmentation in patients with OVCF with intra-disc leakage could prevent SAVF and associated second surgery. The incidence of SAVF also correlated with comorbidities and a history of corticoid use. Thus, we recommend prophylactic vertebral augmentation in selected high-risk patients. Further prospective randomized studies, such as 
Table 5 Univariate logistic regression analysis in the non-prophylactic group

\begin{tabular}{|c|c|c|c|}
\hline Parameters & AVF & Non-AVF & $P$ value \\
\hline Male & 5 (62.5\%) & $8(15.7 \%)$ & \\
\hline Female & $3(37.5 \%)$ & $43(84.3 \%)$ & 0.003 \\
\hline Age & 69.9 [46-83] & $65.8[55-84]$ & 0.325 \\
\hline \multicolumn{4}{|l|}{ Osteoporosis parameters } \\
\hline QCT & $57.0(11.8-105.0)$ & $65.2(7.7-128.4)$ & 0.836 \\
\hline Z score & $-1.56(-0.55$ to -3.07$)$ & -1.51 (0.35 to -3.96$)$ & 0.933 \\
\hline T score & $-3.98(-2.87$ to -4.78$)$ & $-3.98(-1.54$ to -6.18$)$ & 0.991 \\
\hline Comorbidities & $6(75.0 \%)$ & $24(47.1 \%)$ & 0.142 \\
\hline Corticoids use history & 4 (50.0\%) & $2(4.0 \%)$ & 0.002 \\
\hline \multicolumn{4}{|l|}{ Surgery-related } \\
\hline VAS post-op & $1.6[0-4]$ & $1.9[0-6]$ & 0.635 \\
\hline Cement usage & $5.4(1.8-8.0)$ & $5.6(4.0-7.0)$ & 0.602 \\
\hline Levels & & & 0.477 \\
\hline $\mathrm{TL}$ & $5(62.5 \%)$ & $38(74.5 \%)$ & \\
\hline Non-TL & $3(37.5 \%)$ & $13(25.5 \%)$ & \\
\hline Anterior & $3(37.5 \%)$ & $12(23.5 \%)$ & 0.478 \\
\hline Middle & $5(62.5 \%)$ & $33(64.7 \%)$ & \\
\hline Posterior & 0 & $6(11.8)$ & \\
\hline
\end{tabular}

VAS, visual analog scale; QCT, quantitative computed tomography; AVF, adjacent vertebrae fracture; TL, thoracolumbar.

large multicenter clinical trials, should be conducted to confirm our results.

\section{Acknowledgments}

Funding: This work is supported by The Capital Health Research and Development of Special (2020-4-2076) and Beijing JiShuiTan Research Funding (XKGG201814).

\section{Footnote}

Reporting Checklist: The authors have completed the STROBE reporting checklist. Available at http://dx.doi. org/10.21037/apm-21-867

Data Sharing Statement: Available at http://dx.doi. org/10.21037/apm-21-867 
Conflicts of Interest: All authors have completed the ICMJE uniform disclosure form (available at http://dx.doi. org/10.21037/apm-21-867). The authors have no conflicts of interest to declare.

Ethical Statement: The authors are accountable for all aspects of the work in ensuring that questions related to the accuracy or integrity of any part of the work are appropriately investigated and resolved. All procedures performed in this study involving human participants were in accordance with the Declaration of Helsinki (as revised in 2013). The study was designed and conducted following the international guidelines, and was approved and guided by the Ethics Committee of the Beijing Jishuitan Hospital (No. 202012-01) and the director of the Spine Department. Both verbal and written consent about prophylactic vertebral augmentation was obtained before surgery.

Open Access Statement: This is an Open Access article distributed in accordance with the Creative Commons Attribution-NonCommercial-NoDerivs 4.0 International License (CC BY-NC-ND 4.0), which permits the noncommercial replication and distribution of the article with the strict proviso that no changes or edits are made and the original work is properly cited (including links to both the formal publication through the relevant DOI and the license). See: https://creativecommons.org/licenses/by-nc-nd/4.0/.

\section{References}

1. Lindsay R, Silverman SL, Cooper C, et al. Risk of new vertebral fracture in the year following a fracture. JAMA 2001;285:320-3.

2. Svedbom A, Hernlund E, Ivergard M, et al. Osteoporosis in the European Union: a compendium of country-specific reports. Arch Osteoporos 2013;8:137.

3. Garfin SR, Yuan HA, Reiley MA. New technologies in spine: kyphoplasty and vertebroplasty for the treatment of painful osteoporotic compression fractures. Spine (Phila Pa 1976) 2001;26:1511-5.

4. Papanastassiou ID, Phillips FM, Van Meirhaeghe J, et al. Comparing effects of kyphoplasty, vertebroplasty, and nonsurgical management in a systematic review of randomized and non-randomized controlled studies. Eur Spine J 2012;21:1826-43.

5. Ma XL, Xing D, Ma JX, et al. Balloon kyphoplasty versus percutaneous vertebroplasty in treating osteoporotic vertebral compression fracture: grading the evidence through a systematic review and meta-analysis. Eur Spine J 2012;21:1844-59.

6. Bouza C, Lopez-Cuadrado T, Almendro N, et al. Safety of balloon kyphoplasty in the treatment of osteoporotic vertebral compression fractures in Europe: a metaanalysis of randomized controlled trials. Eur Spine J 2015;24:715-23.

7. Krueger A, Bliemel C, Zettl R,et al. Management of pulmonary cement embolism after percutaneous vertebroplasty and kyphoplasty: a systematic review of the literature. Eur Spine J 2009;18:1257-65.

8. Bliemel C, Oberkircher L, Buecking B, et al. Higher incidence of new vertebral fractures following percutaneous vertebroplasty and kyphoplasty--fact or fiction? Acta Orthop Belg 2012;78:220-9.

9. Spross C, Aghayev E, Kocher R, et al. Incidence and risk factors for early adjacent vertebral fractures after balloon kyphoplasty for osteoporotic fractures: analysis of the SWISSspine registry. Eur Spine J 2014;23:1332-8.

10. Hey HW, Tan JH, Tan CS, et al. Subsequent Vertebral Fractures Post Cement Augmentation of the Thoracolumbar Spine: Does it Correlate With Levelspecific Bone Mineral Density Scores? Spine (Phila Pa 1976) 2015;40:1903-9. Erratum in: Spine (Phila Pa 1976) 2016;41:368.

11. Ahn Y, Lee JH, Lee HY, et al. Predictive factors for subsequent vertebral fracture after percutaneous vertebroplasty. J Neurosurg Spine 2008;9:129-36.

12. Jesse MK, Petersen B, Glueck D, et al. Effect of the Location of Endplate Cement Extravasation on Adjacent Level Fracture in Osteoporotic Patients Undergoing Vertebroplasty and Kyphoplasty. Pain Physician 2015;18:E805-14.

13. Diel P, Reuss W, Aghayev E, et al. SWISSspine-a nationwide health technology assessment registry for balloon kyphoplasty: methodology and first results. Spine J 2010;10:961-71.

14. Werner CM, Osterhoff G, Schlickeiser J, et al. Vertebral body stenting versus kyphoplasty for the treatment of osteoporotic vertebral compression fractures: a randomized trial. J Bone Joint Surg Am 2013;95:577-84.

15. Van Meirhaeghe J, Bastian L, Boonen S, et al. A randomized trial of balloon kyphoplasty and nonsurgical management for treating acute vertebral compression fractures: vertebral body kyphosis correction and surgical parameters. Spine (Phila Pa 1976) 2013;38:971-83.

16. Hong SJ, Lee S, Yoon JS, et al. Analysis of intradiscal cement leakage during percutaneous vertebroplasty: 
multivariate study of risk factors emphasizing preoperative MR findings. J Neuroradiol 2014;41:195-201.

17. Baroud G, Nemes J, Heini P, et al. Load shift of the intervertebral disc after a vertebroplasty: a finite-element study. Eur Spine J 2003;12:421-6.

18. Khosla A, Diehn FE, Rad AE, et al. Neither subendplate cement deposition nor cement leakage into the disk space during vertebroplasty significantly affects patient outcomes. Radiology 2012;264:180-6.

19. Rho YJ, Choe WJ, Chun YI. Risk factors predicting the new symptomatic vertebral compression fractures after percutaneous vertebroplasty or kyphoplasty. Eur Spine J 2012;21:905-11.

20. Li YA, Lin CL, Chang MC, et al. Subsequent vertebral fracture after vertebroplasty: incidence and analysis of risk factors. Spine (Phila Pa 1976) 2012;37:179-83.

21. Chiang CK, Wang YH, Yang CY, et al. Prophylactic vertebroplasty may reduce the risk of adjacent intact vertebra from fatigue injury: an ex vivo biomechanical study. Spine (Phila Pa 1976) 2009;34:356-64.

22. Aquarius R, Homminga J, Hosman AJ, et al. Prophylactic vertebroplasty can decrease the fracture risk of adjacent

Cite this article as: Jiang JL, Liu YJ, Xiao B, Zhang GL, Tian W. Prophylactic vertebral augmentation in patients with intra-disc leakage after kyphoplasty. Ann Palliat Med 2021;10(5):5433-5443. doi: 10.21037/apm-21-867 vertebrae: an in vitro cadaveric study. Med Eng Phys 2014;36:944-8.

23. Kurutz M, Varga P, Jakab G. Prophylactic vertebroplasty versus kyphoplasty in osteoporosis: A comprehensive biomechanical matched-pair study by in vitro compressive testing. Med Eng Phys 2019; 65:46-56.

24. Becker S, Garoscio M, Meissner J, et al. Is there an indication for prophylactic balloon kyphoplasty? A pilot study. Clin Orthop Relat Res 2007;458:83-9.

25. Yen CH, Teng MM, Yuan WH, et al. Preventive vertebroplasty for adjacent vertebral bodies: a good solution to reduce adjacent vertebral fracture after percutaneous vertebroplasty. Am J Neuroradiol 2012;33:826-32.

26. Theologis AA, Burch S. Prevention of Acute Proximal Junctional Fractures After Long Thoracolumbar Posterior Fusions for Adult Spinal Deformity Using 2-level Cement Augmentation at the Upper Instrumented Vertebra and the Vertebra 1 Level Proximal to the Upper Instrumented Vertebra. Spine (Phila Pa 1976) 2015;40:1516-26.

(English Language Editor: L. Huleatt) 